\title{
Лексические инновации в мемосфере: названия мемных жанров
}

\section{Lexical innovations in the meme sphere: Names of meme genres}

\begin{abstract}
The development of the Internet gave life to Internet memes. Their diversity and rapid growth contributed to the formation of the memosphere, the development of which is accompanied by the emergence of lexical innovations. These include language memes and the names of meme genres. All of them are the result of linguistic creativity, which in relation to the names of meme genres, covers several stages: English loanwords for the name of the meme genre, their adaptation in Russian, changes in semantics, and preference for specific neologisms. The concept of lexical innovation was apprehended on the foundation of Markovsky's concept. The study of lexical innovations was carried out within the framework of the structural-semantic direction, as well as on the basis of the theory of Kotelova and the concepts of Rakhmanova and Suzdaltseva. Studies have shown that semantic changes in the names of meme genres are associated with a denotation change. Changes in the semantics of word loaning are very dynamic as English loanwords enable the swift naming of new realities. This tendency towards the internationalization of vocabulary is related to the Internet and the memosphere. The obtained results fill the gap in the study of vocabulary related to the memosphere. A few studies of meme genres relate to their description and analysis, yet do not focus on the semantic and graphic modification of loanwords. This work presents the unprecedented mechanisms and stages of the formation of meme genres names.
\end{abstract}

Keywords: memosphere, language creativity, language innovations, lexical innovations

Olga Makarowska, Uniwersytet im. Adama Mickiewicza w Poznaniu, Poznań - Polska, filin@ wp.pl, ORCID ID: https://orcid.org/0000-0002-3687-7993

Введение. Понятие мемосфера, еще не получившее определения в специальной литературе - даже в монографии Магдалены Каминьской (2017) оно не дефинируется - можно интерпретировать как совокупность интернет-мемов, функционирующих в (не)интернетной реальности. Ее развитие сопровождается появлением лексических инноваций (ЛИ), одни из которых выступают в текстовой части вербальных и вербально-невербальных мемов, другие - в наименованиях составляющих мемосферы. Поскольку ЛИ, явля- 
ющиеся компонентом названий мемных жанров ${ }^{1}$, почти не изучены, целью настоящей работы является рассмотрение их специфики. Главные задачи уточнить понятия языковые и лингвистические инновации; выявить основные типы ЛИ, встречающиеся в наименованиях интернет-мемов, которые дали названия мемным жанрам; представить особенности их образования и изменение значения. Исследуемый материал - указанные номинации, собранные методом сплошной выборки с (не)специализированных сайтов (на одних сайтах мемы только размещены, например lolkot.ru, motivators.ru, на других они объяснены, см. memoteka.com/Мемы). Дата последнего обращения к сайтам с мемами одинакова - 08.09.2019.

Теория и методы. В основе понимания инноваций лежит концепция Анджея Марковского, согласно которой языковой инноващией является „каждый новый элемент в тексте, узусе, норме или системе" от нового произношения звука до новых синтаксических связей (Markowski 41). Языковые инновации не отождествляются с инновациями в языке, ибо последние оказывают влияние „на функционирование системы языка в целом или отдельных его подсистем" (Korâkovceva 84). Сказанное обычно не касается языковых инноваций, прежде всего окказионализмов и авторских неологизмов.

Языковые инновации - результат языковой креативности, чья суть заключается „в создании новых форм, потенциально разрешенных системой языка" (Moskver, электронный ресурс). Особое место среди них занимают ЛИ (в терминологии Марковского инновации дополняющие), т. е. „словообразовательные неологизмы, неосемантизмы, внутренние и внешние заимствования, а также фразеологические неологизмы” (Markowski 42).

В специальной литературе термины лексическая инновация, новообразование, неологизм отождествляются или размежевываются (Mel'nik, Štehman, электронный ресурс). Лингвисты, рассматривающие новые слова, нередко следуют определенной традиции, напр., в польском „диахроническом языкознании относительно новых лексических единиц применяется, скорее, термин лексическая инновация" (Chomik, Krajewska 11). Ранее Данута Буттлер писала, что термин новообразование чаще используется в работах, посвященных новым словам в речи, неологизм - в работах, изучающих язык писателей (Buttler 236). Не вдаваясь в детали, призна́ем взаимозаменяемость терминов лексическая инновация (далее ЛИ) и неологизм. Под новообразованием же будут пониматься неологизмы словообразовательные и те, которые получены путем намеренного искажения родного/заимствованного слова,

${ }^{1}$ Ввиду издательских ограничений не рассматриваются: а) названия явлений, чей статус как мема требует обоснования, напр., языковых единиц (слов, фраз, текстов типа ржунимагу, Чи да?, стишки-порошки и пр.); б) названия разновидностей мемных жанров (лолдоги, песоматрицы и др.). 
сопровождающегося изменениями семантики и графической стороны единицы (при использовании средств только родного языка).

Рассмотрение ЛИ производится в структурно-семантическом ключе (подробнее об этом направлении в изучении ЛИ см. Ророva 13), поэтому применяются такие методы исследования, как описание и анализ. Выявление новизны ЛИ в мемосфере проводится в рамках конкретно-исторической теории Надежды Котеловой, в соответствии с конкретизаторами времени и пространства (Kotelova 189-190). Установление причин возникновения ЛИ основано на концепции Людмилы Рахмановой и Веры Суздальцевой (Rahmanova, Suzdal'ceva 87).

Степень новизны ЛИ. Конкретизация названий мемных жанров согласно параметру „языковое пространство” показывает, что почти все номинации являются новыми в национальном языке, литературных речи и языке. Исключение составляет частично ассимилированное слово мем, поэтому оно не рассматривается.

Точно установить время вхождения номинаций в русский язык сложно. Зафиксировано лишь первое появление лексемы фотожаба-2004 год (Krongauz 227). Котоматрица и лолкот начинают употребляться позже - соответствующие сайты были созданы в 2006 г., хотя фото котов с подписями размещались в Сети с 2003 г. Слово демотиватор известно примерно с 2006 г. (по некоторым данным с 2008 г.), аткрытка - с 2009 г. (время регистрации сайта Atkritka.com, cy-pr.com), мотиватор как интернет-мем - с 2010 г., эдвайc - c 2011 г. (memepedia.ru). Многие мемы перекочевали в Рунет после 2008 г. с открывшегося в 2003 г. англоязычного имиджборда 4chan, напр., фейсы (memepedia.ru). Если учесть, что неологизмы - это „слова, возникшие на памяти применяющего их поколения" (Golovin 90), то названия мемных жанров - новое явление для поколений, рожденных до 1990 г.

Причины возникновения ЛИ - необходимость наименования новой реалии (эдвайс, гиф и др.) и необходимость указания на „частичное изменение предмета" в меняющейся действительности (Rahmanova, Suzdal'ceva 87), что касается кото-, зоо- и звероматриц. Дело в том, что изображения животных с юмористическими подписями публиковались в XIX веке, также в виде открыток, напр., Агитаторъ Шперлинга, 1826 г. (стоя на бочке, пудель „обращается с речью” к окружившим его собакам, etoretro.ru). Популярность в Сети подобных фотоизображений животных обусловила необходимость их номинации.

Избыточность - недостаточность ЛИ. Названия почти всех мемных жанров восполняют лексическую недостаточность. Избыточность проявляется в номинации жанра котоматрицы (синонимы - зооматрица и звероматрица) и аткрытки (синоним - мем-открытка). 
В названиях мемных жанров встречаются ЛИ двух типов - новообразования и внешние заимствования, в т. ч. иноязычные вкрапления. Ввиду неоднозначности понятия иноязычные вкрапления и разнообразных подходов к его определению и соотношению с заимствованиями (Norlusenân, электронный ресурс), отметим, что, в нашем понимании, иноязычные вкрапления - языковые элементы (буквы, знаки, артикли и пр.) или единицы (от слова до текста), заимствованные из другого языка и не адаптированные графически.

Новообразования получены в результате: а) сложения двух производящих основ (мем-открытка $a^{2}$ ), в т. ч. с помощью интерфикса (котоматрица и звероматрища); б) присоединения префиксоида к производящей основе (зооматрица); в) искажения исходной лексической единицы (аткрытка и фотожаба).

Праобразом аткрытки служат электронные открытки - someecards, появившиеся в 2006 г. (Makarowska 182-183). Слово someecards (слитное написание англ. somee-cards, т. е. какие-то электронные открытки) не вошло в русский язык. Вместо него используется искаженный вариант слова omкрытка (Krongauz 175).

Слово фотожаба (изображение как эффект фотомонтажа) - пример мнимого сложения. Правдоподобно оно есть искажение искаженного заимствования: Adobe Photoshop $\rightarrow$ Фотожоп (сленговое название Фотошопа) $\rightarrow$ Фотожаба (с опорой на работу Белова, Belov 206-207).

Семантика новообразований, точнее, двух из приведенных выше, указывает на искажение: а) исходного материала, так как фотожаба представляет фальсифицированный фрагмент действительности, запечатленный на фото, обработанном в Фотошопе (Belov 206); б) функции предмета, ибо аткрытки не предназначены для пересылки короткого личного сообщения. Переход данных сетевых картинок в разряд мемов, сказывается и на их значении:

1) фотожаба - изначально „смешной и/или абсурдный коллаж, созданный на основе другого изображения при помощи графического редактора" (Krongauz 227). Актуально это значение дополняется следующими: интернет-мем в виде картинки, полученной путем креативной переработки изображения в Фотошопе, с надписью или без нее; результат креативной переработки изображения в Фотошопе, который может быть использован в разных интернет-мемах;

${ }^{2}$ Слово мем-открытки встречается на странице портала Nibler.ru, открывшегося в 2010 г. Момент первого употребления слова не установлен - страница с мем-открытками могла появиться позже. 
2) аткрытка - изначально „жанр юмористических изображений, напоминающих традиционную почтовую открытку” (Krongauz 175). Актуальное значение - интернет-мем, в виде однотонной, пастельного цвета картинки „установленного размера, объема и образца с черно-белым рисунком справа и юмористической надписью слева" (Makarowska 183).

Выявить значение компонента -матрица в соответствующих номинациях сложно. Оно может восходить к значениям следующих лексических единиц: фотоматрица, матрица как литейная, штамповочная, печатная форма или матрица как таблица, состоящая из математических элементов, битовая матрица (Moskvin 383; Vaulina 52; Kuznecov 525) и др. Часть из перечисленных матриц-реалий объединяет прямоугольная форма, часть - возможность воспроизведения какого-то предмета, что характерно для мемных „матриц”, но не закреплено в семантике слов зоо- и звероматрииа. То есть непосредственная смысловая связь перечисленных матриц с матрицей как фотографией животных с надписью не прослеживается.

Котоматрица имеет два значения: 1) фотография котов с надписями; 2) фотография любых животных с надписями. Зоо- и звероматрищы употребляются во втором значении. Словарные определения этих трех ЛИ отсутствуют.

Внешние заимствования. Все ЛИ заимствованы исключительно из английского языка, напр., демотиваторы или демотивационные постеры от англ. demotivators или demotivational posters - демотивационные плакаты (Kamińska 2010: 66).

Mотиваторы или мотивационные постеры от англ. motivators или motivational posters, т. е. мотивационные плакаты. Мемы появились позже демотиваторов, как их альтернатива или антипод, и характерны именно для Рунета (утверждение дано на правах предположения, ибо дата появления мотиваторов не зафиксирована).

Фейсы, реже фэйсы (от англ. face 'лицо') - общее название фотографий или рисунков лиц, отражающих эмоции, чувства, реакцию на происходящее. Фейсы используются в комиксах, напр., joyreactor.cс. Дублеты рейдж фейсы и рейджфейсы (от англ. face 'лицо' и rage 'ярость') употребляется редко.

Cmpun от англ. strip 'полоса'; комик-стрип, стрип-комикс, комикс-стрип от англ. comic strip 'комикс, комикс-полоска'. Комик-стрип используются не часто, предположительно из-за совпадения со словом комик, называющим артиста комедийных жанров.

Эдвайс (первоначально адвайс) от англ. advice 'совет'. В 2011 г. в Рунете появились мемы с Собакой-советчицей, созданные по образцу мема Advice Dog, придуманного в 2006 г. Эваном Херрингтоном (memepedia.ru; но существует и другая версия появления мема, см. memoteka.com) - на фоне из 
цветных треугольников было размещено фото головы лабрадора. Причисление эдвайсов к макросам (напр., Krongauz 199-200) мало обосновано, ибо последние представляют самостоятельный жанр.

Макро от англ. слова тасro 'макро, т. е. большой, крупный'. Чаще употребляется ЛИ макрос, т. е. macro во множественном числе - macros (Krongauz 199). К ним сначала относились Reaction Images (картинки-реакции) без текста, позже - изображения с надписью, выполненной прописными белыми буквами, шрифтом без засечек (memepedia.ru).

$\boldsymbol{\Gamma} \boldsymbol{u \phi}$ от англ. акронима GIF, т. е. Graphics Interchange Format - „формат хранения изображений” (Belov 22); в мемосфере - анимированные картинки.

Лолкот (редко лолкэт) от англ. lolcat, составленного из акронима lol и слова cat 'кот'. Lol интерпретируется как laugh(ing) outloud 'громко смеюсь', или как lots of laughs 'много смеха' (Belov 118; Krongauz 63). Лолкот сочетание кириллического варианта слова lol и переведенного на русский язык слова cat. Первые рунетские лолкоты создавались по примеру англоязычных: как фото котов с надписью, обычно выполненной белыми буквами (шрифт без засечек) и содержащей орфографические и грамматические ошибки (Kamińska 2010: 67), например НЕ ЕШ/ПОДУМОЙ (кот сидит в банке из-под сока, lurkmore.to).

Основной особенностью семантики заимствований является ее изменение ввиду модификаций, связанных с денотатом и касающихся места функционирования, формы, статуса и пр., как то:

\section{1. Демотиватор}

Употребляемые в работе названия иконоид и текстон ранее были введены нами для обозначения изображенческой и текстовой части креолизованных мемов.

ПЕРВОНАЧАЛЬНОЕ ЗНАЧЕНИЕ: создающая аТмосферу безЫсходности пародия на плакаты, вывешенные в учреждениях с целью мотивирования служащих и посетителей (на тему см. Kamińska 2010: 66; Krongauz 187-188).

ИЗМЕНЕНИЕ ДЕНОТАТА ${ }^{3}:$ предмет объективной реальности $\rightarrow$ интернет-мем.

\section{ИЗМЕНЕНИЕ ПЕРВОНАЧАЛЬНОЙ ФОРМЫ ИНТЕРНЕТ-МЕМА}

\footnotetext{
${ }^{3}$ Сначала приводится первоначальное значение/вид изображения, после стрелочки модификации.
} 
ОБРАМЛЕНИЕ: черный фон и белая рамка $\rightarrow$ появление цветных фонов и рамок.

ИКОНОИД: фотография $\rightarrow$ появление рисунков, текстов, коллажей, плакатов, гифов и пр.

ТЕКСТОН: слоган/лозунг крупным шрифтом белого цвета с засечками и пояснение мелким шрифтом без засечек $\rightarrow$ появление текстов любого жанра, цитат, однословных подписей и пр., использование любого шрифта, в т. ч. цветного.

СОДЕРЖАНИЕ: навевающее уныние $\rightarrow$ любое, в т. ч. шуточное, философское, мотивирующее и др.

ИЗМЕНЕНИЕ ЗНАЧЕНИЯ (здесь и далее учитываются только определения, данные в научных и словарных источниках)

Первое доступное определение (2010): „Изображение, состоящее из рисунка в рамке и комментирующей его надписи-слогана, составленное по определенному формату” (Ŝurina 2010, электронный ресурс).

Словарное определение (2016): „Изображение в черной рамке с текстом на нижней и самой широкой стороне рамки, имеющим философский или юмористический характер" (Krongauz 187).

Актуальное значение (2019): интернет-мем, стандартный формат которого, при наличии разных отклонений от него, включает прямоугольное изображение в белой рамке, размещенное на черном фоне, и набранную белыми буквами подпись любого содержания.

\section{2. Мотиватор}

Формирование мотиваторов по отношению к демотиваторам развивалось в двух направлениях: „антиподном” и альтернативном. Мотиваторы-альтернативы (название условно) отличаются от демотиваторов лишь мотивирующим содержанием. Мотиваторы-антиподы - полная противоположность демотиваторов.

ПЕРВОНАЧАЛЬНОЕ ЗНАЧЕНИЕ: мотивирующие пЛакатЫ.

ИЗМЕНЕНИЕ ДЕНОТАТА: предмет объективной реальности $\rightarrow$ интернет-мем.

ИЗМЕНЕНИЕ ПЕРВОНАЧАЛЬНОЙ ФОРМЫ ИНТЕРНЕТ-МЕМА

ОБРАМЛЕНИЕ: мотиватор-антипод - голубой фон и белая рамка $\rightarrow$ появление цветных фонов $\rightarrow$ отсутствие фонов и белых рамок; мотиватор-альтернатива - без изменений, визуальная сторона, как у демотиватора.

ИКОНОИД: мотиватор-антипод - позитивный снимок/рисунок $\rightarrow$ появление текстов, демотивирующих изображений, демотиваторов, коллажей 
и др. $\rightarrow$ появление мотиваторов, состоящих из фона светлого цвета с надписью белыми буквами без засечек; мотиватор-альтернатива - демотивирующие изображения $\rightarrow$ добавляются позитивные изображения.

ТЕКСТОН: мотиватор-антипод - без изменений, т. е. текст любого жанра, цитаты и пр. Первая часть текста (в т. ч. слоган) набрана большими белыми буквами, вторая - более мелким шрифтом без засечек; мотиватор-альтернатива - без изменений, т. е. текст любого жанра, цитаты и пр. Одна часть текста (в т. ч. и вторая) написана крупным шрифтом белого цвета, другая - мелкими/крупными буквами белого цвета с засечками или без них.

СОДЕРЖАНИЕ: мотивирующее $\rightarrow$ появляются подписи о грусти, одиночестве.

\section{ИЗМЕНЕНИЕ ЗНАЧЕНИЯ}

Первое доступное определение (2015): „Смысловая картина или фотография, используемая в интернете, сопровождающаяся соответствующим смысловым текстом. Мотиватор может быть как в цветной рамке, так и без нее" (Grehova, Zav'âlova, электронный ресурс).

Словарное определение: в настоящий момент отсутствует.

Актуальное значение (2019): 1) интернет-мем, стандартный формат которого, при наличии разных отклонений от него, включает позитивное изображение прямоугольной формы в белой рамке, размещенное на голубом фоне, и набранную белыми буквами подпись чаще мотивирующего содержания; 2) демотиваторы с подписью мотивирующего содержания.

\section{3. Фейсы (лица)}

Заметим, что причисление к фейсам текстовых смайлов (напр., Смайлик бросает стол, memepedia.ru) мало обосновано.

ПЕРВОНАЧАЛЬНОЕ ЗНАЧЕНИЕ: сетевая картинка - нарисованные лица, передающие эмоцию или реакцию, потенциальные персонажи комиксов. Заметим, что первый фейс FFFUUU появился в первом Яростном комиксе (memepedia.ru).

ИЗМЕНЕНИЕ ДЕНОТАТА: рисунок в Интернете $\rightarrow$ интернет-мем и персонаж интернет-комиксов.

ИЗМЕНЕНИЕ ПЕРВОНАЧАЛЬНОЙ ФОРМЫ ИНТЕРНЕТ-МЕМА

ИЗМЕНЕНИЕ РИСУНКА: черно-белые изображения, иногда с цветным элементом (Мимимишечка) $\rightarrow$ раскрашивание мемов, добавление (не)цветных деталей, частей тела; перерисовка фейсов, в т. ч. со сменой выражаемой эмоции, напр., представление троллфейса в виде мексиканца или ужасающимся; преображение фейсов в гифы. 
ПОПОЛНЕНИЕ ФЕЙСОВ: появление цветных мемов (Орехус) и черно-белых рисунков, сделанных с фотографий известных лиц (Мистер Бин).

ИЗМЕНЕНИЕ ЗНАЧЕНИЯ

Первое доступное определение (2016): „Карикатурные изображения лиц, используемые в комиксах и в интернет-мемах" (Kačmazova, электронный ресурс).

Словарное определение: в настоящий момент отсутствует.

Актуальное значение (2019): интернет-мемы в виде нарисованных персонажей (карикатурных лиц, известных персон), которые передают конкретную реакцию, эмоцию или состояние, главные герои Яростных комиксов; часто используются в других интернет-мемах.

\section{4. Стрип-комикс}

В специальной литературе отсутствует четкое разделение интернет-комиксов (веб-комиксов), стрипов и Яростных комиксов, хотя это не одно и то же. Например, Елена Нежура отделяет стрипы и интернет-комиксы, не определяя первые, а вторые дефинируя как ,лаконичные КрТ (креолизованные тексты - О. М.), включающие обычно 2-4 изображения, иллюстрирующие веселую историю" (Nežura, электронный ресурс). Последующее же описание интернет-комикса и приведенная в качестве примера картинка относятся к Яростным комиксам (Nežura, электронный ресурс).

ПЕРВОНАЧАЛЬНОЕ ЗНАЧЕНИЕ: комикс, размещенный в газете или журнале и состоящий из 2-4 изображений, расположенных горизонтально/ вертикально в ряд или в виде квадрата.

ИЗМЕНЕНИЕ ДЕНОТАТА: предмет объективной реальности $\rightarrow$ интернет-мем.

ИЗМЕНЕНИЕ ПЕРВОНАЧАЛЬНОЙ ФОРМЫ ИНТЕРНЕТ-МЕМА

СПОСОБ СОЗДАНИЯ: ручная рисовка $\rightarrow$ компьютерная рисовка картинок $\rightarrow$ появление комиксов, состоящих из мультипликационных кадров, и фотокомиксов ${ }^{4}$, включающих также фотожабы.

КОЛИЧЕСТВО КАДРОВ: 2-4 картинки $\rightarrow$ увеличение их числа до 10 и более.

ТЕКСТОН: всегда в наличии $\rightarrow$ в фотокомиксах может отсутствовать.

ИЗМЕНЕНИЕ ЗНАЧЕНИЯ

${ }^{4}$ Фотокомиксы близки к стрипам по форме и к Яростным комиксам по содержанию, так как представляют ситуацию и эмотивную реакцию на нее. 
Первое доступное определение (2014): „Разновидность комиксов, представляющих собой ленту из нескольких кадров, выстроенных в ряд (чаще горизонтально)" (Uhova, электронный ресурс).

Словарное определение: в настоящий момент отсутствует.

Актуальное значение (2019): интернет-мем в виде комикса, обычно состоящего из 2 и более изображений (рисунков, фотографий, фотожаб, кадров из мультфильмов) с надписями или без них и представляющего какую-то историю.

\section{5. Эдвайс}

ПЕРВОНАЧАЛЬНОЕ ЗНАЧЕНИЕ: Заимствованная с англоязЫчных имиджбордов сетевая картинка с собакой на цветном фоне, дающей вредные советы (Воруй убивай).

ИЗМЕНЕНИЕ ДЕНОТАТА: картинка в интернете $\rightarrow$ интернет-мем.

ИЗМЕНЕНИЕ ПЕРВОНАЧАЛЬНОЙ ФОРМЫ ИНТЕРНЕТ-МЕМА

ФОН: радужные треугольники $\rightarrow$ использование треугольников любой цветовой гаммы и однотонных $\rightarrow$ появление других геометрических форм типа квадратов, диагональных полос и узоров, напр. фон мема Омская птий.

ПЕРСОНАЖИ: Собака-советчица $\rightarrow$ появление других животных, людей, мемов типа троллфейса, героев кинофильмов и аниме.

ФОРМА ПРЕДСТАВЛЕНИЯ ПЕРСОНАЖЕЙ: фотография $\rightarrow$ появЛение рисунков, фотожаб, кадров из кинофильмов и аниме.

ТЕКСТОН: вредные советы $\rightarrow$ изречения, шутки, раскрывающие тематику, заданную характером персонажа (Злая Училка, Типичный ботан и др.) $\rightarrow$ разнообразные по содержанию высказывания (от философских до пошлых).

\section{ИЗМЕНЕНИЕ ЗНАЧЕНИЯ}

Первое доступное определение (2012): „КрТ (креолизованный текст O.M.), состоящий из изображения определенного персонажа на квадратном поле (часто - многоцветном) и подписи, отражающей типичное мышление или поведение этого героя, какую-либо ситуацию из его жизни" (Nežura, электронный ресурс).

Словарное определение: приводится только описание мема (Krongauz 200).

Актуальное значение (2019): интернет-мем, стандартный формат которого, при наличии разных отклонений от него, включает изображение персонажа, размещенного в центре квадратной картинки на фоне из разноцветных треугольников, и набранную белыми буквами надпись. 


\section{6. Макрос}

ПЕРВОНАЧАЛЬНОЕ ЗНАЧЕНИЕ: фото, размещенное в интернете, персонаж которого изображает определенную эмоцию, реакцию, состояние.

ИЗМЕНЕНИЕ ДЕНОТАТА: сетевая картинка $\rightarrow$ интернет-мем.

ИЗМЕНЕНИЕ ПЕРВОНАЧАЛЬНОЙ ФОРМЫ ИНТЕРНЕТ-МЕМА

ИКОНОИД: фотография персонажа, обычно кадры из (мульт)фильмов, компьютерных игр $\rightarrow$ появление коллажей и фотоснимков предметов, фотожаб, перерисованных с фотоснимков персонажей, фейсов и других мемов.

ТЕКСТОН: отсутствие надписи $\rightarrow$ появление текста, который „транслирует конкретное событие" (Uhova, электронный ресурс) $\rightarrow$ текст любого содержания.

ИЗМЕНЕНИЕ ЗНАЧЕНИЯ

Первое доступное определение (2014): „Картинка с текстом, которую используют в онлайн-дискуссиях для более наглядного и остроумного выражения своего мнения" (Uhova, электронный ресурс).

Словарное определение (2016): „Графический шаблон, используемый для создания смешных картинок с подписями характерным белым шрифтом, а также сама получившаяся картинка" (Krongauz 199).

Актуальное значение (2019): интернет-мем в виде картинки прямоугольной формы, персонаж которой с помощью невербальных средств передает определенную эмоцию, реакцию или состояние; изображение часто сопровождается надписью, выполненной белыми буквами.

\section{7. Гиф}

ПЕРВОНАЧАЛЬНОЕ ЗНАЧЕНИЕ: формаТ растровой графики.

ИЗМЕНЕНИЕ ДЕНОТАТА: тип упаковки изображений $\rightarrow$ гиф-анимация $\rightarrow$ интернет-мем.

ИЗМЕНЕНИЕ ПЕРВОНАЧАЛЬНОЙ ФОРМЫ ИНТЕРНЕТ-МЕМА: статичное изображение $\rightarrow$ анимированное изображение.

ИЗМЕНЕНИЕ ЗНАЧЕНИЯ

Первое доступное определение (2014): „Анимированные картинки, короткие невербальные зарисовки, фиксирующие, как правило, некую эмоциональную реакцию (от ужаса до восторга; весьма популярны гифы, буквально демонстрирующие фейсnалм 'стыд') - и поэтому чаще всего использующиеся в комментариях" (Ŝrina 2014, электронный ресурс).

Словарное определение (2007): „Графические файлы с расширением GIF" (Belov 76). 
Актуальное значение (2019): интернет-мем в виде анимированного изображения; может использоваться в других мемах, например демотиваторах.

\section{8. Лолкот}

ПЕРВОНАЧАЛЬНОЕ ЗНАЧЕНИЕ: фоТография кошки с надПисью юмористического характера.

ИЗМЕНЕНИЕ ДЕНОТАТА: сетевая картинка $\rightarrow$ инТернет-мем.

ИЗМЕНЕНИЕ ПЕРВОНАЧАЛЬНОЙ ФОРМЫ ИНТЕРНЕТ-МЕМА

ИКОНОИД: только фото кошек $\rightarrow$ появление фото кошек с другими животными и/или человеком.

ТЕКСТОН: текст с разными ошибками $\rightarrow$ отсутствие намеренно сделанных ошибок; надпись крупным шрифтом белого цвета без засечек $\rightarrow$ появление цветных и декоративных шрифтов.

ИЗМЕНЕНИЕ ЗНАЧЕНИЯ

Первое доступное определение: в настоящий момент отсутствует.

Словарное определение: в настоящий момент отсутствует.

Актуальное значение (2019): интернет-мем в виде фотографии кошки, в т. ч. в обществе других животных и/или человека, с надписью юмористического характера, сделанной обычно белыми прописными буквами без засечек.

Иноязычные вкрапления, касающиеся названий мемных жанров:

- сосуществуют со своим графически адаптированным вариантом, например Rage Faces и рейдж фейсы (то же, что фейсы);

- сопровождаются переводом на русский язык, например RageFaces (Яростные лииа), Rage Comics (Яростные комиксы), Reaction Images (картинки-реакиии), см. memepedia.ru;

- используются как нетранслитерированный компонент в дефисном гибридном образовании, например rage-комикс (Яростный комикс). Название дефисное гибридное образование впервые употреблено в работе Елены Снеговой (Snegova, электронный ресурс).

Основная особенность семантики названий Reaction Images и Яpocmные комиксы - неизменность. Под первыми понимается макрос без надписи; под вторыми - комикс, обычно состоящий из 2-4 изображений с надписями или без них и представляющий какую-то историю, главными персонажами которой являются фейсы. Отождествление Rage Comics с фейсами (Krongauz $136)$ и интернет-комиксами (Nežura, электронный ресурс) мало оправдано.

В мемосфере Яростные комиксы и Reaction Images обрели статус интернет-мема; название Reaction Images, вытесняемое словом макрос, в Рунете употребляется редко. 
Результаты. Анализ ЛИ показал, что новообразования создавались с помощью узуальных и неузуальных (аткрытка, фотожаба) способов. Был выявлен редкий способ образования ЛИ - двойное искажение заимствования.

Среди заимствований выделены иноязычные вкрапления, гибриды (лолкот, стрип-комикс), прямые заимствования (фейс, стрип, гиф и пр.), из которых лишь часть структурно совпадает с англоязычными прототипами (гиф, демотиватор). Отмечается также наличие дублетов (эдвайс - адвайс и др.).

Об освоении заимствований, кроме вкраплений, говорит их кириллический облик и морфологическая освоенность. Грамматически освоены также ЛИ с переосмысленным значением множественного числа (макрос) и rage-комикс.

В семантике большинства ЛИ, независимо от их типа, наблюдаются такие изменения, как полисемантизация (фотожаба, котоматрища, мотиватор), в т. ч. сужение значения (аткрытка, стрип, гиф), уточнение (демотиватор, фейсы, макрос, лолкот) и расширение (эдвайс). Семантически неизменными остаются зоо- и звероматрицы, Reaction Images и Яростные комиксы.

Каждая ЛИ, кроме редко употребляемых (мем-открытка, Rage Faces, peйдж фeйсы и Reaction Images), является названием мемных жанров. Поэтому важно, что, во-первых, в семантике наименований мемов содержится описание жанрового образца. Во-вторых, что высвечивание значений мемов в энциклопедическом ракурсе позволяет обогатить их внутреннюю структуру еще одним значением - „название мемного интернет-жанра”.

Путь вхождения ЛИ в национальный язык (а не только в русский как язык-приемник) показывает, что каждая относится к однократным внутренним или к двойным внешне-внутренним заимствованиям. Первые проникли в национальный язык из языка интернет-пользователей (аткрытка и „матрицы”) или из интернет-сленга (фотожаба). Вторые сначала пришли из английского языка в интернет-сленг (гиф) или в язык интернет-пользователей (все остальные заимствования), откуда переместились в национальный язык.

Заключение. Анализ лексического материала показывает, что основным источником ЛИ при наименовании мемных жанров является английский язык, а важнейшей тенденцией в данной области - заимствование. Использование английских заимствований обусловлено не только необходимостью быстрого восполнения пробелов в номинации новых реалий действительности. В этом проявляется также тенденция к интернационализации лексики, связанной с Интернетом вообще и мемосферой в частности.

Кроме того, была раскрыта зависимость семантической изменяемости рассмотренных заимствований и неизменности отдельных иноязычных 
вкраплений от модификации денотата и от ее отсутствия соответственно. При этом изменения семантики заимствований носят весьма динамичный характер, о чем свидетельствует достаточно быстрая дезактуализация их значений, зафиксированных в словарях. Исследование выявило необходимость унификации графического облика ряда названий мемных жанров, а также создания базы источников, позволяющих отслеживать изменения, происходящие в семантике рассмотренных названий, и фиксировать их в открытой справочной литературе.

Дальнейшие исследования. Малоизученность ЛИ не позволила в рамках одной работы охватить ряд вопросов, связанных с их особенностями, поэтому перспективы исследования весьма широки. Они касаются семантического соотношения ЛИ с этимонами, установления стадий семантической адаптации, проблемы словарной фиксации ЛИ, раскрытия специфики названий разновидностей мемных жанров (комбо, лолдог, песоматрица и др.), а также рассмотрения словообразовательных гнезд (вершинами которых являются названия мемных жанров) и семантики их производных. Безусловно, это лишь определенная часть в целом масштабных и всесторонних исследований лексических инноваций в мемосфере.

\section{Библиография}

Belov, Nikolaj. Slovar' molodežnogo i internet-slenga. Minsk, Harvest, 2007.

Buttler, Danuta. „Neologizm i terminy pokrewne”. Poradnik Językowy, 5-6 (200-201), 1962, s. 235-244.

Chomik, Milena, Monika Krajewska. Od nominacji do kreacji. Toruń, Wydawnictwo Naukowe Uniwersytetu Mikołaja Kopernika, 2011.

Golovin, Boris. Vvedenie v âzykoznanie. Moskva, Vysšaâ škola, 1977.

Grehova, Elena, Irina Zav'âlova. Motivatory i ih social'naâ značimost'. Web. 08.09.2019. https:// лендюц.екатеринбург.рф/file/1af478f6e4f969b72292e9abb5a6f1fc.

Kačmazova, Alina. Kreolizovannyj tekst kak žanr internet-diskursa. Web. 08.09.2019. https://elibrary.ru/item.asp?id=27381288.

Kamińska, Magdalena. Memosfera. Wprowadzenie do cyberkulturoznawstwa. Poznań, Galeria Miejska Arsenał, 2017.

Kamińska, Magdalena. „Memy, signa i sigile. Perspektywy e-semiologii”. Kultura medialnie zapośredniczona. Badania nad mediami w optyce kulturoznawczej. Red. Wojciech Chyła, Magdalena Kamińska, Piotr Kędziora, Marta Kosińska. Poznań, Galeria Miejska Arsenał, 2010, s. $43-55$.

Korâkovceva, Elena. „Nomina actionis s novymi internacional'nymi formantami v russkom âzyke epoki postmoderna: v sopostavlenii s pol'skim i češskim âzykami”. Studia Rossica Posnaniensia, 35, 2010, s. 83-92.

Kotelova, Nadežda. Izbrannye raboty. Sankt-Peterburg, Nestor-Istoriâ, 2015.

Krongauz, Maksim et al. Slovar' âzyka interneta.ru. Moskva, Ast-Press Kniga, 2016. 
Kuznecov, Sergej. Bol'šoj tolkovyj slovar' russkogo âzyka. Sankt-Peterburg, Norint, 1998.

Makarowska, Olga. „Žanry memetičeskogo internet-diskursa: IQkartka/atkrytka”. Studia Rossica Posnaniensia, 43, 2018, s. 181-192.

Markowski, Andrzej. Kultura języka polskiego. Teoria. Zagadnienia leksykalne. Warszawa, Wydawnictwo Naukowe PWN, 2005.

Mel'nik, Ûliâ, Elena Štehman. K voprosu o statuse neologizma v sovremennoj lingvistike. Web. 08.09.2019. https://elibrary.ru/item.asp?id=24123255.

Moskver, Ekaterina. O meste tvorčeskogo ili „,kreativnogo” potenciala russkogo âzyka v praktike prepodavaniâ russkogo âzyka kak inostrannogo. Web. 08.09.2019. http://rlj.americancouncils. org/issues/59/files/Moskver_2009.pdf.

Moskvin, Anatolij. Bol'šoj slovar' inostrannyh slov. Moskva, Centrpoligraf, 2002.

Nežura, Elena. Novye tipy kreolizovannyh tekstov v kommunikativnom prostranstve interneta. Web. 08.09.2019. https://docplayer.ru/27020129-Novye-tipy-kreolizovannyh-tekstov-v-kommunikativnom-prostranstve-interneta-e-a-nezhura.html.

Norlusenân, Vâčeslav. Inoâzyčnye vkrapleniâ: sovremennoe sostoânie problemy. Web. 08.09.2019. https://elibrary.ru/item.asp?id=15119753.

Popova, Tat'âna. Russkaâ neologiâ i neografiâ. Ekaterinburg, Izdatel'stvo GOU-VPO UGTU-UP, 2005.

Rahmanova, Lûdmila, Vera Suzdal'ceva. Sovremennyj russkij âzyk. Leksika. Frazeologiâ. Morfologiâ. Moskva, Izdatel'stvo MGU, 1997.

Snegova, Elena. O leksikografičeskom predstavlenii složnosostavnyh slov s inoâzyčnym komponentom. Web. 08.09.2019. https://elibrary.ru/item.asp?id=17216524.

Surina, Ûliâ. Internet-memy: problema tipologii. 2014. Web. 08.09.2019. https://elibrary.ru/item. asp? $\mathrm{id}=23235205$.

Ŝurina, Ûliâ. Komičeskie kreolizovannye teksty v internet-kommunikacii. 2010. Web. 08.09.2019. https://elibrary.ru/item.asp?id=15119759.

Uhova, Larisa. Žanrovoe svoeobrazie kommunikativnogo prostranstva social'nyh setej. Web. 08.09.2019. https://elibrary.ru/item.asp?id=26052840.

Vaulina, Ekaterina. Informatika. Tolkovyj slovar'. Moskva, Èksmo, 2005.

http://joyreactor.cc/post/236096

\section{Интернет-источники}

https://lurkmore.to/Файл:Podumoi.jpg

https://memepedia.ru/about-macros/

https://memepedia.ru/advice-animals/

https://memepedia.ru/comp-react-faces/

https://memepedia.ru/fffuuu/

https://memepedia.ru/flipping-tables/

https://memepedia.ru/rage-comics/

https://memoteka.com/Advice_Dog

https://memoteka.com/Мемы

http://motivators.ru

http://nibler.ru/pics/20272-mem-otkrytki.html

https://www.cy-pr.com/a/atkritka.com

https://www.etoretro. ru/pic92618.htm?sort_field=image_date\&sort=DESC

lolkot.ru 
